\title{
Atividade Física e Saúde
}

\author{
José Maria Santarem*
}

Os profissionais da área médica em geral têm plena consciência de que a saúde das pessoas depende da interação de fatores ambientais com a constituição genética dos indivíduos. No que diz respeito à atividade física, o consenso atual é no sentido de que os exercícios habituais sejam benéficos para a saúde das pessoas. Os efeitos da atividade física reconhecidos como salutares são os que afastam as pessoas de condições estatisticamente relacionadas com a ocorrência de doenças. Os mais importantes são o alívio de tensões emocionais, a normalização dos níveis e do perfil bioquímico das gorduras do sangue, a melhor eficiência do metabolismo glicídico, o estímulo ao aumento da massa muscular, o aumento da massa óssea e a diminuição do tecido adiposo. A evolução dos conhecimentos em fisiologia do esforço tem demonstrado efeitos dos exercícios físicos sobre o sistema endócrino e imunológico que ampliam as possibilidades de utilização profilática e terapêutica da atividade física. A questão da longevidade e sua possível relação com uma vida fisicamente ativa é um aspecto ainda não esclarecido mas que continua sendo bastante estudado.

Entendendo saúde como uma situação de bem-estar físico, mental e social, o aprimoramento do desempenho motor do organismo conseqüente à atividade física deve ser considerado um fator salutar. A melhora da aptidão física permite que as tarefas da vida diária sejam realizadas com menor esforço, e assim sendo as pessoas passam a não se sentir limitadas fisicamente para atividades que gostariam de realizar. Esta situação é conhecida como boa qualidade de vida. Os idosos constituem o modelo ideal para se estudar a importância da atividade física na qualidade de vida porque muitos deles são sedentários de longa data e desta maneira perdem gradativamente a aptidão para os esforços. Estudos com idosos demonstraram que as qualidades de aptidão física mais importantes para a qualidade de vida são a flexibilidade e a força. Evidentemente a coordenação neuromuscular é fundamental para qualquer ato motor, mas este aspecto da aptidão física somente está diminuindo de maneira importante na vigência de condições 
patológicas. A flexibilidade diminui gradativamente com o sedentarismo e pode chegar a graus que impedem atividades importantes da vida diária. O mesmo ocorre com a força muscular, necessária para movimentar o peso do corpo ou objetos. Um aspecto de alta relevância referente à contribuição da força muscular para a qualidade de vida apenas recentemente foi compreendido. Trata-se da diminuição da intensidade dos esforços. A homeostase durante exercícios físicos é afetada na razão direta da intensidade do esforço. Quanto maior for o porcentual de capacidade contrátil muscular utilizado em uma atividade, maior será a intensidade do esforço e conseqüentemente mais acentuada a quebra da homeostase, com elevações também proporcionais da pressão arterial e da freqüência cardíaca. Por esta razão idosos com pouca força muscular ficam extremamente ofegantes ao levantar-se de uma cadeira ou subir um lance de escadas. Quando estas pessoas aumentam a força muscular conseguem realizar os mesmos esforços com menores repercussões hemodinâmicas.

A auto-estima das pessoas também contribui para a saúde no sentido de que quando alguém se aceita como é terá conseguido uma situação de bem-estar emocional. Evidentemente a auto-estima tem muitos aspectos, sendo a aparência física um dos mais importantes. Sublimar a insatisfação com o próprio físico pode ser uma solução para este problema, mas modificar o corpo pode ser até mais fácil e certamente mais gratificante. A atividade física associada a alguns cuidados de alimentação é o único caminho realmente eficiente para aprimorar a forma do corpo. Os efeitos são devidos ao aumento da massa muscular e à redução do tecido adiposo.

Um fato interessante é que quando pensamos em atividade física freqüentemente imaginamos pessoas em trajes da moda realizando alguma atividade esportiva. Todavia, muitos dos trabalhos científicos que documentaram efeitos salutares dos exercícios físicos estudaram trabalhadores braçais urbanos e populações rurais. Tudo leva a crer que tanto a atividade física esportiva quanto a laborativa possuam os mesmos efeitos salutares, desde que os exercícios sejam habituais e não excessivos. O esporte, no entanto, é a opção mais prática para atividade física das pessoas que vivem em cidades e que possuem trabalho sedentário. Uma questão que se impõe é saber se existem modalidades esportivas mais salutares do que outras. Do ponto de vista dos efeitos fisiológicos a diferença entre as modalidades esportivas é o estímulo maior ou menor para o desenvolvimento diferenciado das diversas qualidades de aptidão física. Considerando que não existe relação entre o grau de aprimoramento das qualidades de aptidão física com os indicadores de saúde, pode-se afirmar que a escolha da modalidade esportiva deve ocorrer em função de fatores como o gosto pessoal e o nível de preparo físico da pessoa. Evidentemente existem modalidades que para serem praticadas exigem um bom condicionamento físico prévio.

A ginástica em academias é uma das formas de atividade física esportiva mais populares em todo o mundo. Nas academias os exercícios têm o objetivo básico de aprimorar a aptidão e modelar o corpo, enquanto que nos esportes em geral esses benefícios são secundários: o objetivo principal é dominar técnicas de desempenho. O trabalho proposto na maioria das academias utiliza exercícios com pesos associados a exercícios suaves e prolongados classificados como aeróbios. Esta associação se justifica para que o condicionamento físico seja o mais completo possível. Os exercícios com pesos são os mais eficientes para aumentar a massa muscular e estimular ao mesmo tempo várias qualidades de aptidão física como a força, a flexibilidade, a potência e a resistência para esforços de alta intensidade. Os exercícios aeróbios estimulam a resistência para esforços de baixa intensidade. Algumas especulações levaram à noção popular de que os exercícios aeróbios são os mais importantes para a saúde e os únicos que estimulam o emagrecimento. Não existe documentação científica apoiando estes conceitos. Ao contrário, está documentado que qualquer tipo de exercício estimula a movimentação de gordura, apenas em momentos diferentes, e como já vimos, a saúde não se relaciona com o grau de aprimoramento de nenhuma qualidade de aptidão física em particular. Assim sendo, a ginástica com pesos pode ser utilizada isoladamente quando não houver interesse em um condicionamento físico completo, e esta é realmente a indicação mais sensata para pessoas debilitadas. Nos aparelhos de musculação todos os fatores do treinamento podem ser facilmente controlados e adaptados à 
condição física do praticante. Desta maneira não costumam ocorrer excessos de carga, velocidade, ritmo e amplitude de movimentos, entre outros fatores. A ausência de movimentos bruscos e de choques entre pessoas também contribui para a segurança dos exercícios com pesos. Desde que não se utilizem cargas máximas em contrações musculares isométricas e em apnéia, os aumentos de pressão arterial e de freqüência cardíaca são discretos neste tipo de atividade física, que apresenta também uma relação oferta/demanda de $\mathrm{O}_{2}$ para o miocárdio bastante segura. A experiência do CECAFI - Centro de Estudos em Ciências da Atividade Física da Disciplina de
Geriatria da Faculdade de Medicina da USP é altamente favorável à utilização dos exercícios com pesos para idosos, em concordância com outros centros internacionais.

Concluindo, podemos afirmar que as pessoas em busca de saúde e forma física devem dedicarse habitualmente a algum tipo de atividade física. A ginástica em academias ou mesmo residencial bem orientada pode ser a opção mais viável para a maioria das pessoas. O tipo de exercício realizado determina quais as qualidades de aptidão física que serão mais desenvolvidas. Do ponto de vista da saúde qualquer tipo de exercício será benéfico desde que habitual e não excessivo. 